a

\title{
AIRCRAFT WATER VAPOR MEASUREMENTS UTILIZING AN ALUMINUM OXIDE HYGROMETER
}

(NASA-TM-X-70475) AIRCRAFT WATER VAPOR HEASUREHENTS OTILIZING AN ALUMINUN OXIDE HYGRONETER (NASA) 28 p HC $\$ 3.50$

\section{ERNEST HILSENRATH}

GSFC - GODDARD SPACE FLIGHT CENTER GREENBELT, MARYLAND 
AIRCRAFT WATER VAPOR MEASUREMENTS

UTILIZING AN ALUMINUM OXIDE HYGROMETER

Ernest Hilsenrath

Laboratory for Meteorology

and Earth Sciences

September 1973

GODDARD SPACE FLIGHT CENTER

Greenbelt, Maryland 


\title{
AIRCRAFT WATER VAPOR MEASUREMENTS
}

UTILIZING AN ALUMINUM OXIDE HYGROMETER

\author{
Ernest Hilsenrath \\ Laboratory for Meteorology \\ and Earth Sciences
}

\begin{abstract}
A hygrometer for water vapor measurements from an aircraft was developed. An aluminum oxide hygrometer mounted in an aircraft Rosemount air temperature scoop was flown on the NASA Convair 990 and on a USAF B-57 aircraft. Water vapor measurements from the Convair 990 were conducted up to $40,000 \mathrm{ft}$ with penetration into the stratosphere. Good agreement was obtained with simultaneously flown remote sounders of water vapor. During transcontinental flights the hygrometer demonstrated adequate response to measure the natural variability of water vapor near the tropopause. Rapid response was demonstrated in pursuit of the jet wake of an F-104 at 35,000 ft.
\end{abstract}




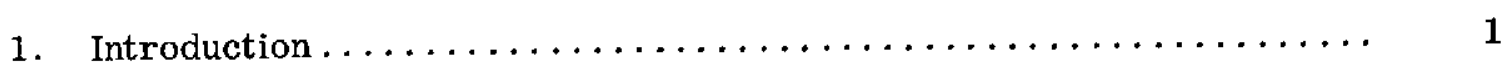

2. Instrumentation and Data Analysis $\ldots \ldots \ldots \ldots \ldots \ldots \ldots \ldots \ldots \ldots$

3. Intercomparison Measurements $\ldots \ldots \ldots \ldots \ldots \ldots \ldots \ldots \ldots \ldots, 4$

4. Water Vapor Measurement Through the Tropopause

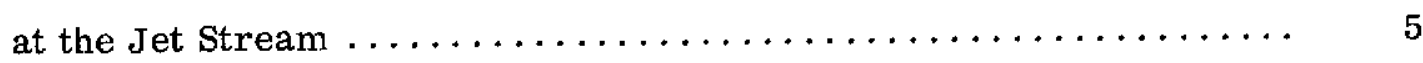

5. Response Time and Jet Wake Encounter................ 7

6. Water Vapor and Ozone Measurements $\ldots \ldots \ldots \ldots \ldots \ldots \ldots \ldots, 9$

7. Conclusions $\ldots \ldots \ldots \ldots \ldots \ldots \ldots \ldots \ldots \ldots \ldots \ldots \ldots \ldots \ldots \ldots \ldots \ldots \ldots \ldots$

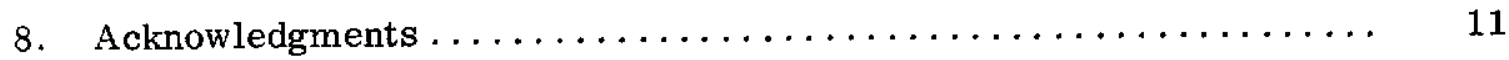

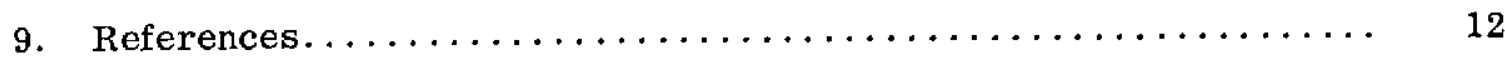

\section{TABLES}

Table

2 Comparison of In-Situ and Radiometrically Measured

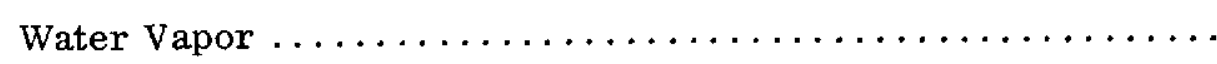




\section{ILLUSTRATIONS}

Figure

$\underline{\text { Page }}$

1 Hygrometer air samplers flown on: a) NASA Convair 990

and b) USAF RB-57. $\ldots \ldots \ldots \ldots \ldots \ldots \ldots \ldots \ldots \ldots \ldots \ldots \ldots$

2 Water vapor distributions and integrated values in vicinity

of weather front over the North Pacific.............. 17

3 Tropopause height and wind analys is reproduced from data

supplied by the U.S. National Weather Service. The aircraft

track is shown by the dots and dashes. .............. 18

4 (A) Aircraft and tropopause heights. Jet stream cores,

locations and positions are denoted by the Js.

(B) Aircraft water vapor and air temperature data.........

5 Water vapor measured by Convair 990 airborne hygrometer

utilizing B-57 air sampler in the wake of a USAF F-104 as

a function of time. One minute data resolution. ........... 20

6 Water vapor measured by Convair 990 airborne hygrometer

utilizing B-57 air sampler in the wake of a USAF F-104 as

a function of time. Three second data resolution. . . . . . . . 21

7 Convair 990 aircraft measured parameters: a) Tropopause

height (from NOAA), b) aircraft altitude, c) ambient temperature,

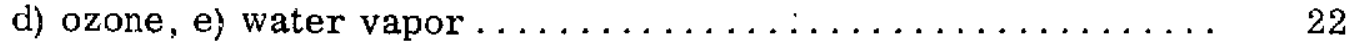

8 Two hundred millibar chart over the North Atlantic. The

dashed line shows the Convair 990 flight path from the

Canary Islands to Bermuda. $\ldots \ldots \ldots \ldots \ldots \ldots \ldots$ 


\section{AIRCRAFT WATER VAPOR MEASUREMENTS \\ UTILIZING AN ALUMINUM OXIDE HYGROMETER}

\section{Introduction}

Water vapor plays an important role in the ultimate disposition of energy in the atmosphere. Near the tropopause it becomes a trace constituent and is still important in the radiation balance of the stratosphere. It has recently become evident that water vapor is also active in the photochemistry of the stratosphere. Because of the sharp decrease in the water vapor concentration with increasing altitude, detailed measurements near the tropopause can provide information on the exchange processes between the troposphere and stratosphere.

An aluminum oxide hygrometer described by Chleck (1966) was flown on a number of NASA Convair 990 meteorological expeditions to determine the suitability of this sensor for in-situ water vapor measurements in the stratosphere. Specifically, these experiments were conducted to help resolve the question of the hygrometer's sensitivity, response time, and temperature dependence in a flight environment. The aircraft hygrometer was flown in support of remote sensors measuring water vapor and in conjunction with in-situ sensors measuring other atmospheric gases. This paper will describe these experiments and attempt to answer the above questions and demonstrate that the aluminum oxide hygrometer can provide useful meteorological information.

\section{Instrumentation and Data Analysis}

The aluminum oxide hygrometer elements utilized in the experiments described in this paper were manufactured by Panametrics Company. Hygrometer operation and calibration procedures have been described in detail by 
Goodman and Chleck (1969) and will not be repeated here. Calibration curves for the hygrometer elements were provided by the manufacturer and utilized for most of the data reported here. The hygrometer elements were also compared at Goddard Space Flight Center with a Cambridge Systems dew/frost point hygrometer (Francisco and Beaubien, 1965) from frost points of $0 \mathrm{C}$ to $-70 \mathrm{C} a t$ room temperatures and at saturation temperatures. Some hygrometer elements were calibrated at the National Bureau of Standaro's* and were utilized in some aircraft flights or used as references. In all cases the elements flown had an accuracy of about $\pm 3 \mathrm{C}$ frost point temperature over the range of measurements encountered in the flight. Table 1 translates this error bar into percent error of water vapor mixing ratio at the various flight levels. Mixing ratios were computed from the Smithsonian Meteorological Tables (1963) and the U. S. Standard Atmosphere, 1962 (1962).

Figure 1 depicts the aircraft hygrometer air samplers. The air samplex shown in Figure 1a was flown on the NASA Convair 990 in 1971 and 1972. The air sampler shown in Figure 1b was also flown on the Convair 990 in 1972 and on the USAF RB-57 in 1972 and 1973. The air sampler shown in Figure 1a allowed for a direct measurement of the temperature and pressure in the vicinity of the hygrometer sensor. The exchange rate in this sampler is about 30 seconds. The earlier flights demonstrated that this device would not be suitable for stratospheric aircraft water vapor measurements. The instrument did however, provide sufficient meteorological data (to be shown below) to justify the development of a more responsive air sampler, that is, an air sampling system that

*NASA-NBS Interagency Agreement S-70227AG. 
would minimize outgassing from the walls and provide maximum ventilation for the hygrometer sensor.

This more responsive system is shown in Figure $1 \mathrm{~b}$ and designated the B-57 air sampler. An aluminum oxide sensor and a thermistor are mounted in a Teflon sleeve which is located inside a Rosemount Engineering Model 102 deiced total air temperature air scoop. This air scoop has several features which are advantageous to in-situ water vapor measurements: (1) high recovery factor, (2) controlled boundary layers on the scoop surfaces which allow for a truer ambient air sample and allows deicing without significantly heating the incoming air, (3) minimum sensitivity to angle of attack, (4) and contains a centrifugal separator and additional boundary layer control which helps prevent water droplets and large particles from impinging on the sensor.

The air scoop was subjected to wind tunnel tests to determine the temperature, pressure, and flow rates as a function of Mach number, in order to characterize the environment the sensors would be exposed to in flight. The tests were performed from Mach 0.2 to Mach 0.7 at simulated altitudes to 20,000 ft. These tests demonstrated that the recovery factor was nearly one, thus simplifying corrections to the measured dew/frost point temperatures in determining the water vapor concentration. (The difference in the ratio of specific heats $\gamma$, between air and water vapor is neglected in the computation.) The temperature measured by the thermistor mounted next to the hygrometer element was within $2 \mathrm{C}$ of the total temperature measured by the total air temperature sensor on the RB-57 flights thus verifying the wind tunnel data to $60,000 \mathrm{ft}$. From these data the calculated flowrate past the hygrometer sensor at Mach 0.3 is 110 cubic centimeters per second and at Mach 0.6 is 350 cubic centimeters per second. 
The exchange rate of air in this system is about 5000 times greater than in the Convair 990 air sampler, Figure 1a.

Both air samplers were flown simultaneously on the Convair 990 providing a direct comparison. The aluminum oxide sensors' impedence was measured by time sharing electronics. Data from these electronics were fed to the airborne data acquisition system which provided dew/frost point temperature data as well as inertial navigation system (INS) data, available real-time on the Convair 990 . In all flight configurations the air scoops were well above the aircraft boundary layer ensuring a true ambient air sample. The entire air sampler was fabricated from stainless steel and Teflon.

\section{Intercomparison Measurements}

Despite the large number of hours the aluminum oxide sensor has flown on the Convair 990 , the amount of direct comparison data with other instruments is meager. Some comparison data with radiosondes has been shown by Hilsenrath and Coley (1971). In general, these comparisons show good agreement, however in every case the direct comparison of aircraft and balloon measurements has been compromised because of separation of the data in time and space. At the higher altitudes, above $400 \mathrm{mb}$, where there is an abundance of aircraft humidity data and the spatial and time factors are not as critical, the radiosonde humidity data becomes unreliable.

Comparisons have been performed with remote sensors. An example has been described by Rosenkranz, et al (1972), who utilized a microwave spectrometer operating at $1.35 \mathrm{~cm}$ wavelength to infer the integrated water vapor below the aircraft. A similar instrument is now flying on the Nimbus-5 satellite. An example of these comparisons is detailed below. The Convair 990 encountered 
a frontal system in the North Pacific oriented north and south at longitude $142^{\circ} 00 \mathrm{~W}$. Three passes were made over the front. The first was at $33,000 \mathrm{ft}$, at which time the microwave measurement was made. The second and third were at $8000 \mathrm{ft}$ and near the surface, respectively, from the front to $140^{\circ} 45 \mathrm{~W}$ to the east. Figure 2 depicts the results of these measurements.

The line connecting the triangles is the water vapor distribution at the front and the line connecting the circles is the distribution to the east. The integrated water vapor is $4.6 \mathrm{~g} / \mathrm{cm}^{2}$ and $3.3 \mathrm{~g} / \mathrm{cm}^{2}$ respectively. The microwave data yielded $4.3 \mathrm{~g} / \mathrm{cm}^{2}$. The agreement is good, however relies heavily on the water vapor at the lower levels.

On 17 December 1971 , the Convair 990 was flown to test and intercompare a number of instruments for stratospheric composition measurements. The aircraft flight path was to the north from Moffett Field, California, where the tropopause would be encountered over Oregon at $35,000 \mathrm{ft}$. In-situ water vapor data were acquired by an aluminum oxide hygrometer. Dr. P. Kuhn (1972) provided a radiometric measurement of the local water vapor by taking the difference in the measured overburden of water vapor at incremental altitudes. Table 2 summarizes the results of the comparison where the water vapor from the aluminum oxide hygrometer is given for a specific altitude and from the radiometer for an altitude interval.

4. Water Vapor Measurement Through the Tropopause at the Jet Stream An example of aircraft humidity data through the jet stream over the Gulf of Alaska was shown by Allison, et al. (1972), where the in-situ water vapor was compared to Nimbus-4 satellite radiation data in the 6.7 micron water vapor channel. This example demonstrated that dry conditions generally prevailed on 
the cyclonic side of the polar jet stream at $240 \mathrm{mb}$. The following describes another example of humidity measurements in the vicinity of a jet stream.

Figure 3 is a composite of tropopause heights and wind analysis over the western portion of the United States obtained from the NOAA Environmental Data Service with an overlay of the Convair 990 track from Moffet Field, California, to Brownsville, Texas. The portion of the flight indicated by the dots was at $24,000 \mathrm{ft}(400 \mathrm{mb})$, and that shown by dashes was at $33,000 \mathrm{ft}(260 \mathrm{mb})$. The subtropical and subpolar jet stream cores shown by the heavy arrowed lines were at $350 \mathrm{mb}$ and $280 \mathrm{mb}$ respectively. The aircraft measured wind speeds were about 140 knots in the jet cores. Figure $4 \mathrm{a}$ shows estimated tropopause heights along the aircraft track. These heights were derived graphically by interpolating radiosonde data near the aircraft track. The position and height of the jet stream core as well as the aircraft pressure height are also shown in 4a. Figure $4 \mathrm{~b}$ shows the aircraft measured temperature and humidity in mass mixing ratio as a function of latitude. The aircraft encountered the tropopause near $117 \mathrm{~W}$. Though no sharp temperature gradients were detected by the aircraft temperature sensor, the INS indicated a sharp increase in wind speeds to over 120 knots at this location. The driest levels occurred near $114 \mathrm{~W}$ when the aircraft was definitely above the tropopause. The measured mixing ratio was $3 \mu \mathrm{g} / \mathrm{g}$, very dry for $400 \mathrm{mb}$, but typical for stratospheric air Mastenbrook (1971). The tropopause height increased as the aircraft continued east. The water vapor reached $22 \mu \mathrm{g} / \mathrm{g}$ near $111 \mathrm{~W}$. Measurements were resumed at $109 \mathrm{~W}$ where the aircraft was flying at $260 \mathrm{mb}$, again above the tropopause, and the measured mixing ratio was $3 \mu \mathrm{g} / \mathrm{g}$. The aircraft again passed through the tropopause at $105 \mathrm{~W}$ and the subtropical jet core at $103 \mathrm{~W}$. The water vapor 
increased to $25 \mu \mathrm{g} / \mathrm{g}$ at which point the aircraft began its descent into Brownsville.

These measurements and those described by Allison, et al. (1972) are consistent with observations of Briggs and Roach (1963) who found steep gradients in the water vapor and ozone isopleths near the tropopause gap with downward bulges to as low as $400 \mathrm{mb}$. The observations and model proposed by Danielson (1968) in the vicinity of the jet stream core also substantiate these observations. The Briggs and Roach (1963) measurements were performed with a frost point hygrometer which gave detailed measurements in the vicinity of the jet stream core, while the Convair 990 measurements demonstrated that the horizontal water vapor distribution in the upper troposphere tends to follow the tropopause heights.

All of the above data were obtained with the less responsive air sampler shown in Figure 1a, where the air exchange rates through the sampling volume was about 30 seconds. However, because of the appreciable amount of absorbtion and desorbtion of water vapor on the air samplex walls at low humidity levels, the actual response time of the system is appreciably larger. By comparing measured water vapor profiles from aircraft ascent and descent data a response time of 2 to 3 minutes is assigned to the data described above. This would amount to about one degree of longitude resolution in the above example.

\section{Response Time and Jet Wake Encounter}

In November 1972 a series of aircraft air sampling measurements were conducted with the Convair 990 as part of the NASA Stratospheric Jet Wake Experiment. The following is a description of the water vapor measurements 
obtained during an encounter with the jet wake of a USAF F-104 deployed from Edwards Air Force Base, California. On this occasion both air samplers shown in Figure, 1 were flown side by side.

Figure 5 depicts the measured water vapor mixing ratios encountered in the jet wake. All the data was acquired at 35,000 $\mathrm{ft}$. The data are plotted once per minute which was available real-time from the airborne computer. There was no contrail, therefore the turbulence created by the F-104 was the only indicator as to the position of the wake. The variability shown in the data is mainly due to the movement of the Convair 990 in and out of the wake. The measurements began at about six miles away to about $1 / 4$ mile at which time the F-104 afterburners were activated.

Figure 6 represents an expanded time section of the same data shown in Figure 5, however the data has been taken off the real-time strip chart recorder at three second intervals when the Convair 990 was nearly $1 / 4$ mile from the F-104. The distinct peaks shown in the figure are associated with the Convair 990 bouncing in and out of the wake. The saturated water vapor mixing ratio, determined by the ambient air temperature, is indicated at $134 \mu \mathrm{g} / \mathrm{g}$. The maximum water vapor content measured during this encounter was about $136 \mu \mathrm{g} / \mathrm{g}$ which was achieved in six seconds. Therefore it is concluded that the hygrometer did respond to the maximum amount of water vapor that could exist in the wake in six seconds. The decay in the water vapor level indicates that fall time of the hygrometer is comparable. The assumptions that the air temperature is the same in and out of the wake 1/4 mile from the jet exhaust and that the air would be saturated in the jet wake at that distance are valid. The aircraft air temperature sensor indicated no difference in temperature in or out of the wake. 
It should be noted that the data obtained from the air sampler in Figure 1a indicated only a very gradual increase in water vapor during the encounter, thus demonstrating a significant improvement in response time in the B-57 air sampler.

\section{Water Vapor and Ozone Measurements}

An aluminum oxide hygrometer utilizing the B-57 air sampler was flown on an aircraft meteorological expedition to Africa in July 1972. The aircraft was instrumented with a complement of atmospheric composition sensors which included a Komhyr total oxidant meter and a Dasibi optical ozone monitor. These instruments were assembled under the NASA Lewis Research Center's Global Atmospheric Sampling Program (Rudy and Perkins, 1973). Figure 7 shows water vapor and ozone data taken on a flight from the Canary Islands to Bermuda.

Aircraft measured temperature and altitude are also plotted on this figure on a common time scale. The ozone data derived from the Komhyr and Dasibi instruments were within 10 percent of each other during most of the flight. Ozone losses in the sampling system are estimated at less than 20 percent (Rudy and Perkins, 1973). The aircraft track is shown in Figure 8 as a dashed line superimposed on a reproduction of a $200 \mathrm{mb}$ chart over the North Atlantic. The tropopause over the Azores was at $230 \mathrm{mb}$ and $170 \mathrm{mb}$ over Bermuda. From the trough off the coast of Spain going east, the aircraft encountered a region of high, then low, pressures over the mid-Atlantic; then a high over Bermuda. Tropopause height computed by NOAA's National Meteorological Center 6-Layer Numerical Prediction Model is shown in Figure 7. An ATS satellite photo of cloud cover over the Atlantic and observations from the aircraft indicated a heavy cirrus layer near $35 \mathrm{~N}, 45 \mathrm{~W}$ or at 14:30 GMT on Figure 7. 
As the aircraft traveled from east to west and increased its altitude it remained near the tropopause. Tropopause encounters could have occurred at 13:30 GMT and 16:00 GMT marked on the aircraft track on Figure 8. The correlation coefficient between the measured water vapor and ozone is about minus 0.3. However, over selected portions of the flight, the anticorrelation is much higher. This result might be expected since the concentration gradients of water vapor and ozone near the tropopause are fairly steep, but opposite in direction, because the stratosphere is poor in water vapor and rich in ozone. With regard to the absolute values, the measured water vapor mixing ratios are in the range of values given by Mastenbrook (1971) between $200-250 \mathrm{mb}$ for July. The lowest value of $20 \mu \mathrm{g} / \mathrm{g}$ is not representative of accepted stratospheric values, if indeed the aircraft did penetrate the tropopause. However, the measurements near 14:30 GMT were very close to saturation levels in the vicinity of the high cirrus layer, thus providing a calibration point for the hygrometer. The two separate instruments yielding very similar ozone values along the flightpath gives high confidence to absolute values within the error bands. The large peaks at 13:30 GMT and 16:00 GMT represent levels of ozone found in the stratosphere or of air of recent stratospheric origin and are coincident with the time of tropopause penetration proposed above.

Regardless of the absolute levels of the measurements, the structure in Figure 7 appears to be real. The fine structure could be due to convective processes near the tropopause or waves in the tropopause itself. Reiter (1963) has suggested "leaflike structure of the tropopause on the anticyclonic side of the jet stream where numerous stable layers slope downward in the troposphere" 
and concludes that "stratospheric air may penetrate into the troposphere and vice versa, without the tropopause changing its position."

\section{Conclusions}

By means of comparisons with other instruments and documentation of specific meteorological encounters to the water vapor measurements an attempt was made to demonstrate that the aluminum oxide hygrometer could provide meaningful meteorological information. Since the aircraft was not dedicated to water vapor measurements in the examples described, a complete investigation of a specific encounter was not accomplished. It was demonstrated that an aluminum oxide hygrometer could provide water vapor measurements from an aircraft within the stated errors. It was also demonstrated that sensors could be mounted in air samplers which would allow maximum response time without damaging the sensor and still allow characterization of the air sample. The agreement with other instruments measuring water vapor was good. The sensor also demonstrated adequate response to measure the natural and artificially induced changes in the water vapor distributions near the tropopause.

\section{Acknowledgments}

The author would like to acknowledge Dr. P. Kuhn of NOAA's Environmental Research Laboratory for the use of his water vapor data in the December 1971 comparison, and Mr. Porter Perkins of the NASA Lewis Research Center who provided ozone data on the flight over the North Atlantic. The cooperation of Panametrics is gratefully acknowledged. To the members of the Airborne Science Office, NASA Ames Research Center, a sincere thanks for their enthusiastic cooperation. A portion of this work was supported by Climatic Impact Assessment Program of the Department of Transportation. 


\section{References}

Allison, I. J., J. Sterenka; G. T: Cherrix, and E. Hilsenrath, 1972. "Meteorological Applications of the Nimbus-4 Temperature-Humidity Infrared Radiometer, 6.7 Micron Channel Data." Bulletin of the American Meteorological Society. Vol. 53, No. 6, pp. 526-535.

Briggs, J., and W. T. Roach, 1963. "Aircraft Observations Near Jet Streams." Royal Meteorological Society Quarterly Journal 89 (380), pp. 225-247.

Chleck, D., 1966. "Aluminum Oxide Hygrometer: Laboratory Performance and Flight Results." Journal of Applied Meteorology, 5(6), pp. 878-885.

Danielson, E. F., 1968. "Stratospheric-Tropospheric Exchange Based on Radioactivity, Ozone and Potential Vorticity." Journal of Atmospheric Science, Vol. 25, pp. 502-518.

Francisco, Charles C., and David J. Beaubien, 1965. "An Automatic Dew Point Hygrometer with Thermoelectric Cooling." Humidity and Moisture Measurement and Control in Science and Industry, Vol. 1, Chap. 17, New York.

Goodman, P., and D. Chleck, 1969. "Calibration of the Panametric Aluminum Oxide Hygrometer." Analysis Instrumentation, (7), p. 233.

Hilsenrath, E., and R. L. Coley, 1971. "Performance of an Aluminum Oxide Hygrometer on the NASA Convair 990 Aircraft Meteorological Observatory." Goddard Space Flight Center X-Document, X-651-71-37.

Kuhn, P., 1972. Private communication.

Mastenbrook, H.J., 1971. "The Variability of Water Vapor in the Stratosphere." Journal of Atmospheric Research, Vol. 28.8, pp. 1495-1501. 
Reiter, E. R., 1963. Jet Stream Meteorology. The University of Chicago Press, p. 100 .

Rosenkranz, P.W., P. T. Barath, J. C. Blum, III, E. J. Johnston, W. B. Tenori, D. H. Staelin, and J. W. Waters, 1972. 'Microwave Radiometric Measurements of Atmospheric Temperatures and Water from an Aircraft." Journal of Geophysical Research, Vol. 77, No. 30, pp. 5833-5844.

Rudy, R. A., and P. J. Perkins, 1973. "Measurement of High-Altitude Air Quality Using Aircraft." NASA TMX-68221.

Smithsonian Meteorological Tables, 1963. Washington, D.C. Published by the Smithsonian Institution No. 4014 prepared by R. J. List. Sixth Revised Edition.

U.S. Standard Atmosphere, 1962. Prepared under the sponsorship of NASA, USAF, USWB. Superintendent of Documents, U.S. Government Printing Office, Washington, D.C. 
Table 1

\begin{tabular}{|c|c|c|c|}
\hline $\begin{array}{l}\text { Altitude } \\
\text { ft } \times 10^{3}\end{array}$ & $\begin{array}{c}\text { Typical } \\
\text { dew/frost } \\
\text { point, Celcius }\end{array}$ & $\begin{array}{l}\text { Water vapor } \\
\text { mixing ratio } \\
\mu \mathrm{g} / \mathrm{g}\end{array}$ & $\begin{array}{c} \pm \text { Percent } \\
\text { error }\end{array}$ \\
\hline 0 & +4 & 5000 & 20 \\
\hline 20 & -35 & 290 & 33 \\
\hline 40 & -75 & 4 & 43 \\
\hline 60 & -85 & 1.8 & 50 \\
\hline
\end{tabular}


Table 2

Comparison of In-Situ and Radiometrically Measured Water Vapor

\begin{tabular}{|c|c|c|c|}
\hline \multicolumn{2}{|c|}{$\mathrm{Al}_{2} \mathrm{O}_{3}$} & \multicolumn{2}{|c|}{ Radiometer } \\
\hline & & & Altitude \\
\hline Altitude & Water vapor & Water vapor & interval \\
\hline $\mathrm{ft} \times 10^{3}$ & $\mu \mathrm{g} / \mathrm{g}$ & $\mu \mathbf{g} / \mathbf{g}$ & $\mathrm{ft} \times 10^{3}$ \\
\hline \multirow[t]{2}{*}{26} & 76 & & \\
\hline & & 45 & $26-28$ \\
\hline \multirow[t]{2}{*}{28} & 66 & & \\
\hline & & 11 & $29-37$ \\
\hline \multirow[t]{2}{*}{37} & 8 & & \\
\hline & & 7.0 & $37-39$ \\
\hline \multirow[t]{2}{*}{39} & 3 & & \\
\hline & & 5.8 & $39-41$ \\
\hline \multirow[t]{2}{*}{41} & 1.5 & & \\
\hline & & 2.4 & $42-43$ \\
\hline \multirow[t]{3}{*}{43} & 1.0 & & \\
\hline & & 1.3 & $43-44$ \\
\hline & & 2.1 & $44-44.5$ \\
\hline 44.5 & 1.0 & & \\
\hline
\end{tabular}


(A)

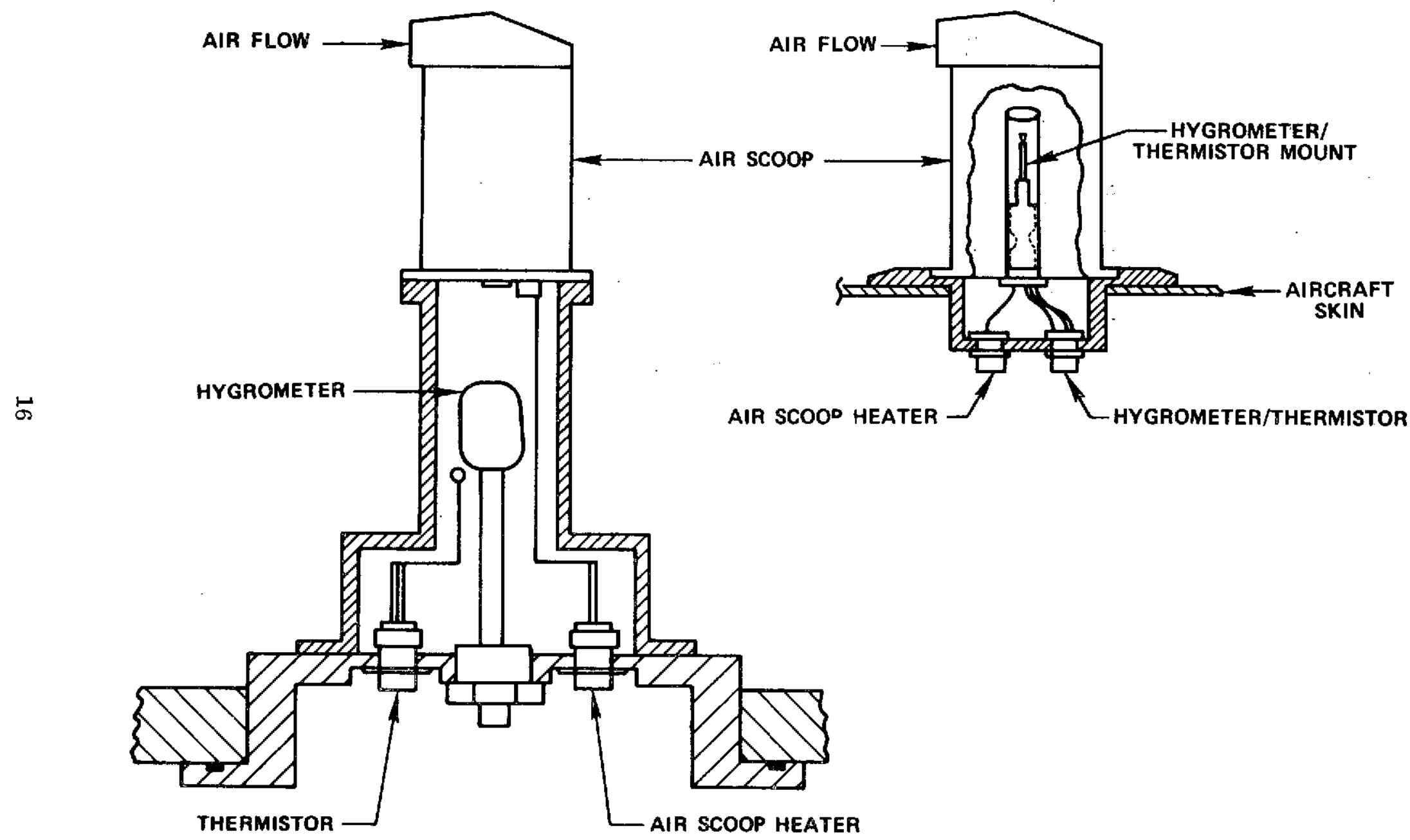

Figure 1. Hygrometer air samplers flown on: a) NASA Convair 990 and b) USAF RB-57 


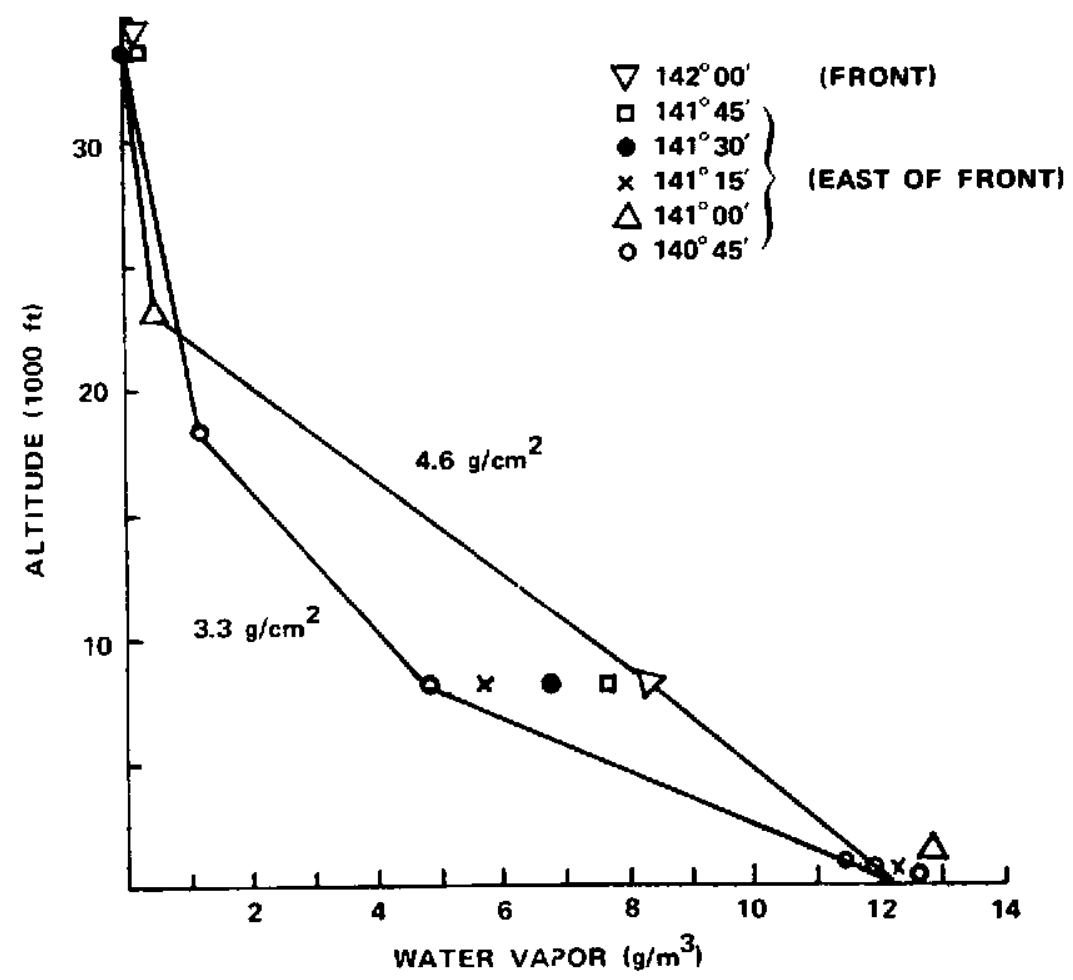

Figure 2. Water vapor distributions and integrated values in vicinity of weather front over the North Pacific 


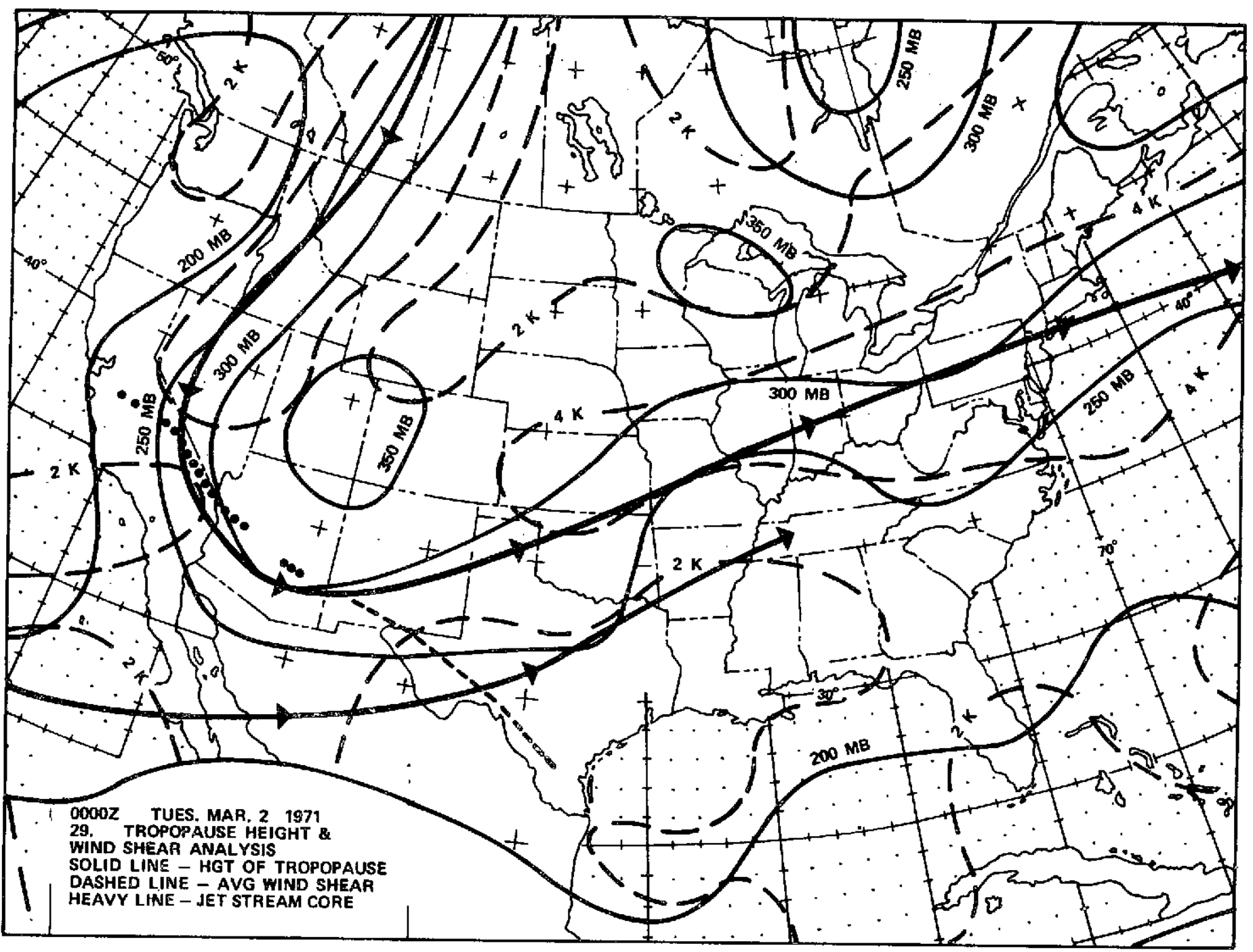

Figure 3. Tropopause height and wind analysis reproduced from data supplied by the U.S. National Weather Service. The aircraft track is shown by the dots and dashes. 
(A)

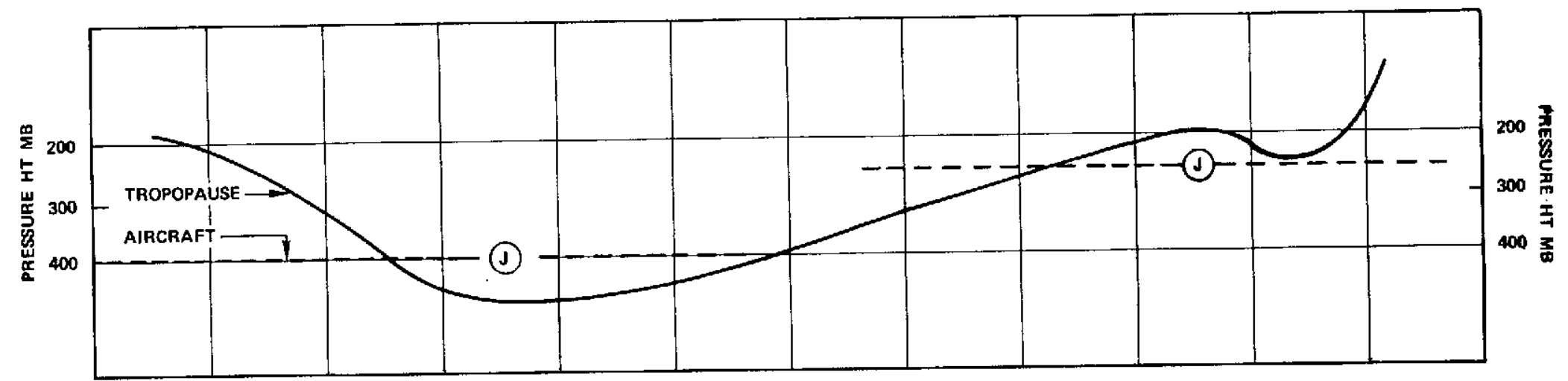

(B)

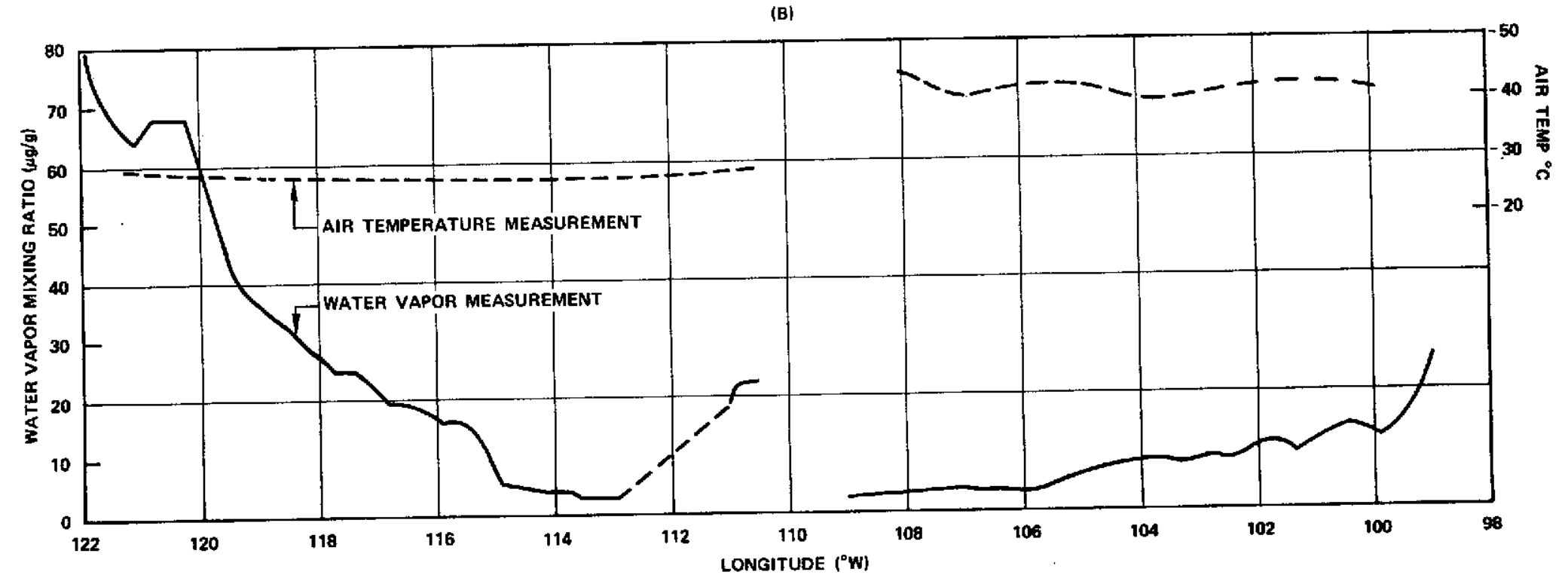

Figure 4. (A) Aircraft and tropopause heights. Jet stream cores, locations and positions are denoted by the Js. (B) Aircraft water vapor and air temperature data. 


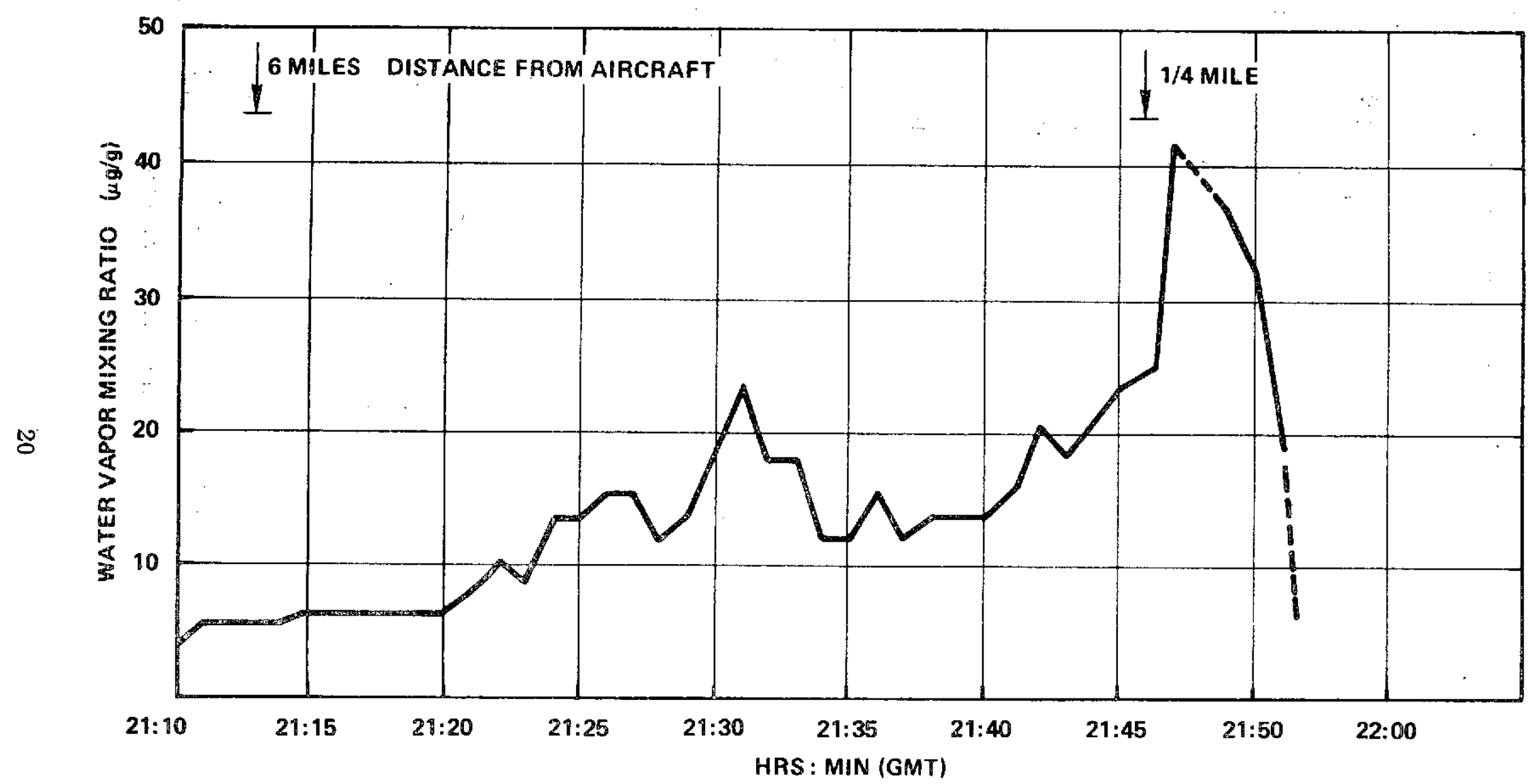

Figure 5. Water vapor measured by Convair 990 airborne hygrometer utilizing B-57 air sampler in the wake of a USAF F-104 as a function of time. One minute data resolution. 


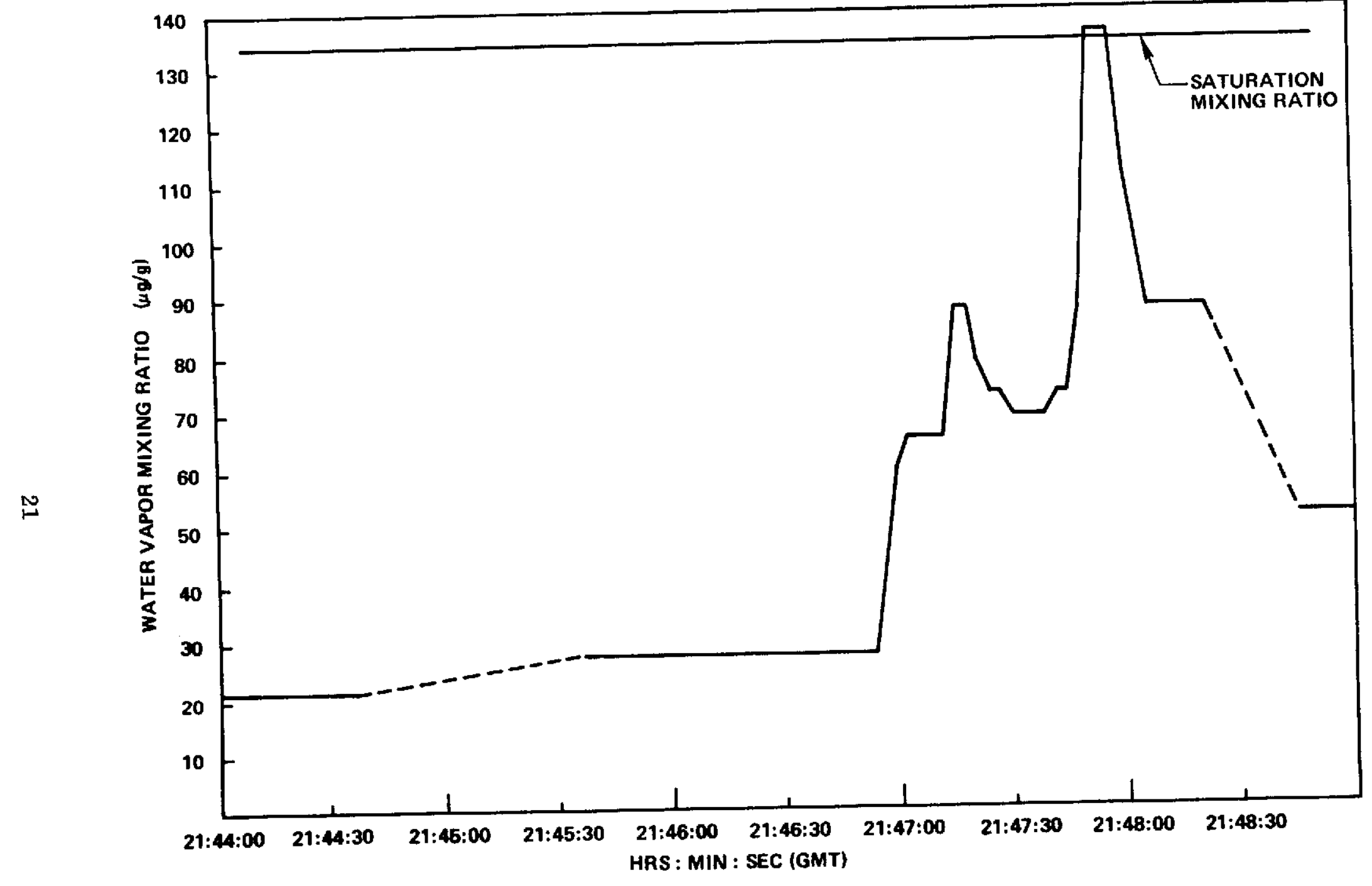

Figure 6. Water vapor measured by Convair 990 airborne hygrometer utilizing B-57 air sampler in the wake of a USAF F-104 as a function of time. Three second data resolution. 


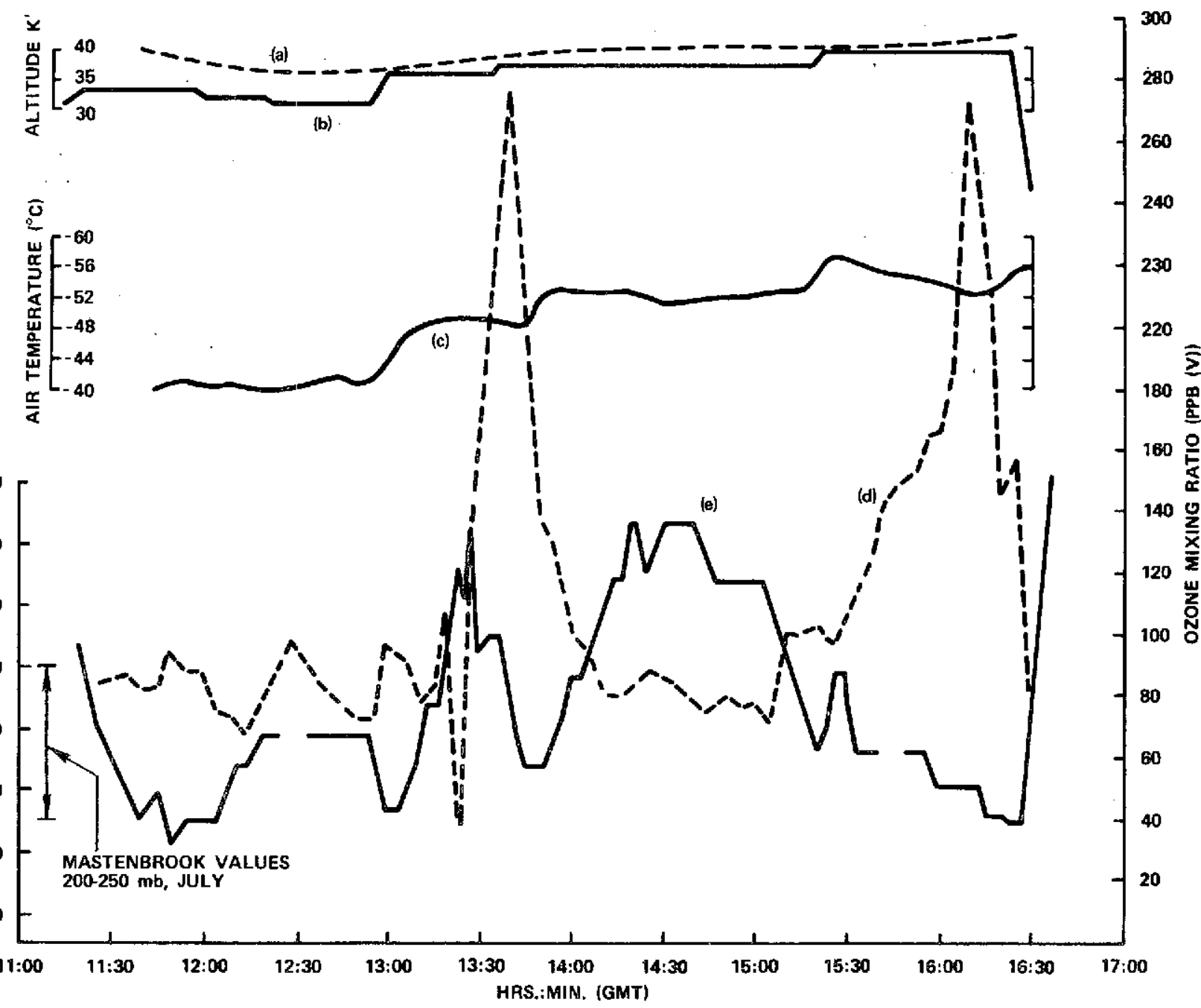

Figure 7. Convair 990 aircraft measured parameters: a) Tropopause height (from NOAA), b) aircraft altitude, c) ambient temperature, d) ozone, e), water vapor. 


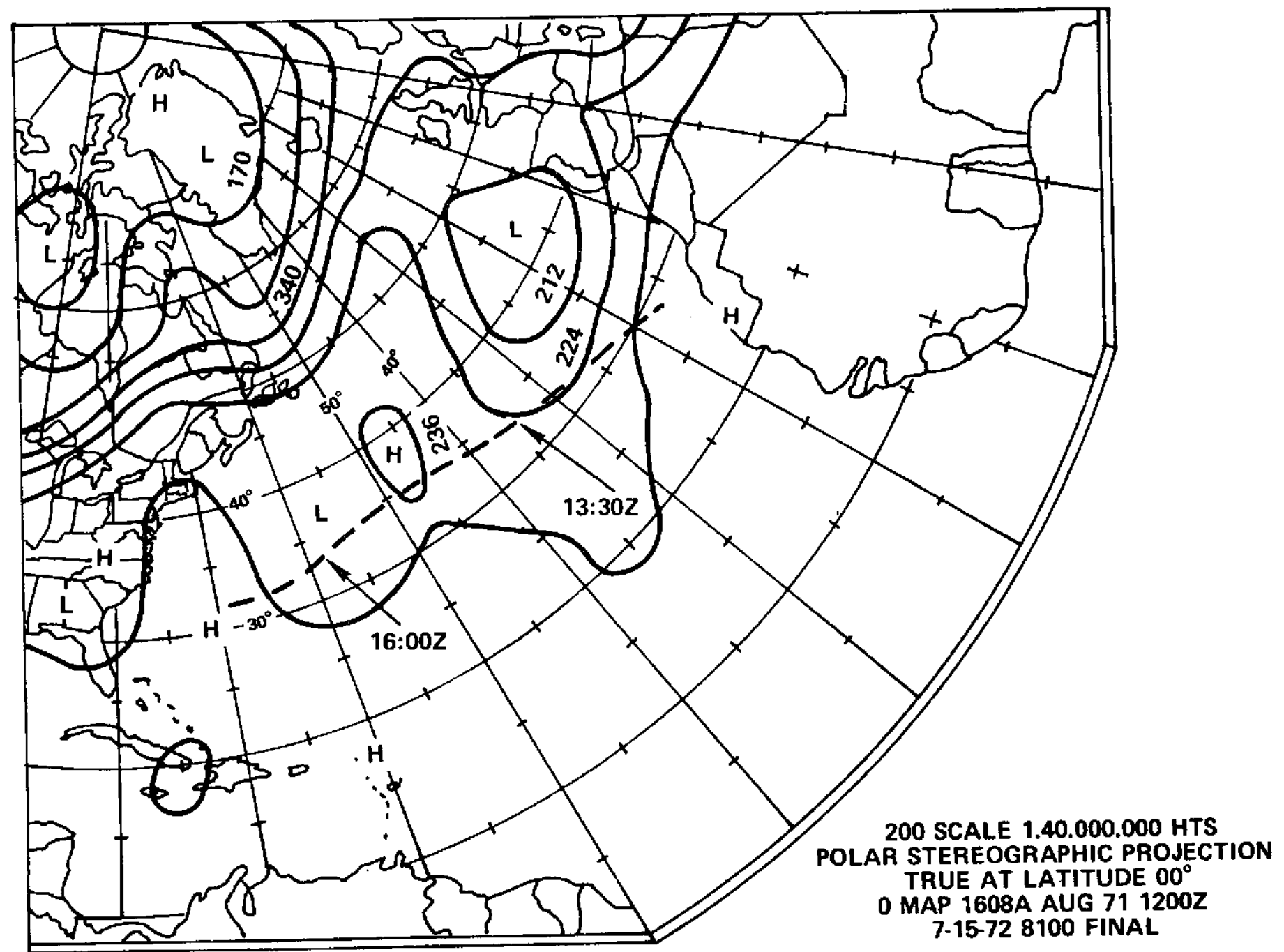

Figure 8. Two hundred millibar chart over the North Atlantic. The dashed line shows the Convair 990 flight path from the Canary Islands to Bermuda. 